Review Article

\title{
Middle turbinate concha bullosa and its relationship with chronic sinusitis: a review
}

\author{
Santosh Kumar Swain* \\ Department of Otorhinolaryngology, Head and Neck Surgery, IMS and SUM hospital, Siksha “O” Anusandhan \\ University, Kalinga Nagar, Bhubaneswar, Odisha, India \\ Received: 10 April 2021 \\ Accepted: 17 May 2021 \\ *Correspondence: \\ Dr. Santosh Kumar Swain, \\ E-mail: santoshvoltaire@yahoo.co.in \\ Copyright: (C) the author(s), publisher and licensee Medip Academy. This is an open-access article distributed under \\ the terms of the Creative Commons Attribution Non-Commercial License, which permits unrestricted non-commercial \\ use, distribution, and reproduction in any medium, provided the original work is properly cited.
}

\begin{abstract}
Sinonasal diseases are serious health issues found in the clinical practice. Sinonasal diseases are often associated with anatomical variants in the sinonasal tract. There are numerous sinonasal anatomical variants found frequently in computed tomography (CT) scans of the paranasal sinuses. Middle turbinate concha bullosa is a common anatomical variant found in the nasal cavity. Pneumatization of the middle turbinate is called as concha bullosa. The pneumatization of the middle turbinate is mostly via the anterior ethmoidal air cells. Pneumatizations through posterior ethmoid air cells are also reported. There are three types of concha bullosa such as lamellar, bulbous and extensive. Majority of the patients with middle turbinate concha bullosa are asymptomatic. Sometimes this is accidentally detected during proper evaluation of the headache. Sometimes the middle turbinate concha bullosa is associated with chronic sinusitis. However, there are very few literatures which correlate the middle turbinate concha bullosa and chronic sinusitis. Although chronic sinusitis is a clinical diagnosis, the imagings like CT scan are useful to assess the extent of the disease and demonstrate the sinonasal anatomy. CT scan of the paranasal sinuses and diagnostic nasal endoscopy are important tests useful for evaluation of the middle turbinate concha bullosa and its relations with chronic sinusitis. This review article discusses on the details of the middle turbinate concha bullosa and its relationship with chronic sinusitis.
\end{abstract}

Keywords: Middle turbinate concha bullosa, Osteomeatal complex, Sinusitis, CT scan

\section{INTRODUCTION}

Chronic sinusitis is a common disease of the paranasal sinuses and a major cause of morbidity for the patients. Few organs in the human body are vulnerable to remarkable inter and intra subject variations as in paranasal sinuses which result in chronic sinusitis. The anatomical variants which interfere with mucociliary drainage of the osteomeatal complex includes concha bullosa, deviated nasal septum, variations of the uncinate process, ethmoid bulla, paradoxical middle turbinate, agger nasi and haller cells. ${ }^{1}$ Concha bullosa is the most common variation of the sinonasal anatomy. ${ }^{1}$ Concha bullosa is defined as pneumatization of the middle turbinate. $^{2} \quad$ Pneumatization of the middle turbinate, concha bullosa is a well-recognized anatomical and clinical problem. This is largely due to increased use of rigid telescopic lens for evaluation of sinonasal passage in routine clinical practice. The concomitant use of the CT scan for the sinonasal diseases has also lead to increased identification of the middle turbinate concha bullosa. The extension of the pneumatization of the middle turbinate originates from the frontal recess or agar nasi cells. Recent document suggest that concha bullosa cannot result sinusitis solely by inducing the mucosal changes and that obstruction may be associated with pathogenesis of sinusitis. This obstruction is usually expected in case of large concha bullosa. ${ }^{3}$ The middle turbinate is an integral part of the ethmoidal labyrinth and act as an important land mark for the surgeon during endoscopic sinus surgery. The 
middle turbinate concha bullosa is a common anatomical variant which can be seen at any age group. ${ }^{2}$ Middle turbinate concha bullosa is the most common anatomical variant inside the nasal cavity and found in patients with sinusitis. There are very few research articles related to the middle turbinate concha bullosa and its possible association to the chronic sinusitis. There are some studies report that middle turbinate concha bullosa may interfere with ventilation of the paranasal sinuses, resulting to sinusitis. However other studies have reported contradictory findings. ${ }^{4,5}$ The purpose of this review article is to discuss details about the relationship between the middle turbinate concha bullosa and sinusitis.

\section{METHODS OF LITERATURE SEARCH}

Research articles regarding concha bullosa and its relationship with chronic sinusitis were searched through a multiple systematic approach. First we conducted an online search of the Scopus, PubMed, Medline and Google scholar databases with the word concha bullosa, chronic sinusitis, middle turbinate, anatomical variations of the sinonasal tract. The abstracts of the published articles were identified by this search method and other articles identified manually from citations. This manuscript reviews the details of middle turbinate concha bullosa and its relationship with chronic sinusitis. This review article presents a baseline from where further prospective trials for anatomical variation like middle turbinate concha bullosa and its manifestations to chronic sinusitis could be designed and which must help as a spur for further research in this important medical issues encountered among patients with concha bullosa.

\section{CONCHA BULLOSA AND ITS EMBRYOLOGY}

The middle turbinate originates from the ethmoid fold of the lateral nasal wall. During third month of fetal development, the ethmoidal air cells begin as evagination from the nasal cavity into the middle meatus of the nose. Some think that the middle turbinate starts pneumatized at this point by posterior ethmoidal air cells. ${ }^{6}$ The functions of the middle turbinate are moisturisation of inspired air, lamination of air flow and deflection of inspired air superiorly towards the olfactory epithelium. ${ }^{6}$ A concha bullosa represents the presence of the air cells inside the middle turbinates. Enlargement of the middle turbinate by pneumatization is a recognized etiology for sinonasal disease. ${ }^{7}$ The pneumatized and enlarged middle turbinate alters the normal air flow and mucous drainage pathways, leading to mucosal edema and obstruction of the osteomeatal complex which result in sinusitis. ${ }^{7}$ Concha bullosa is a common anatomical variant of the sinonasal tract in general population. ${ }^{8}$ It may be unilateral or bilateral. The pneumatized hypertrophied middle turbinate is middle turbinate concha bullosa and considered as a commonest anatomical variation inside the nasal cavity. ${ }^{8}$ The ethmoturbinal and maxilloturbinal are embryological precursors for formation of the nasal turbinates which seen between the eighth and tenth weeks of gestation. The ethmoturbinal component gives rise to uncinate process, the middle turbinate and superior turbinate. The middle turbinate is originated from the medial part of the ethmoid bone. The middle turbinate is divided into three parts depending on its attachment and its orientation in the three dimension space. The anterior one-third of the middle turbinate is in the sagittal plane and attached to the cribriform plate at the junction of the medial and lateral lamella. ${ }^{9}$ It also takes attachment to the frontonasal process of the maxilla. The middle one-third of the middle turbinate in the coronal plane is attached to the lamina papyracea. ${ }^{9}$ The posterior one-third of the middle turbinate is attached in the horizontal pane to the lamina papyracea and perpendicular plate of the palatine bone. ${ }^{9}$ As the middle turbinate elongates in the nasal cavity, the anteriorsuperior stabilization is provided by the cribriform plate, the posterior and lateral stabilization is provided with help of the lamina papyracea. The bony part which gives attachment of the middle turbinate to the lamina papyracea is called as basal lamella. Basal lamella divided the ethmoid sinuses into the anterior and posterior groups. Pneumatization of the middle turbinate is an extension of the normal pneumatization of the ethmoid air cells. ${ }^{10}$

The ethmoidal air cells extend into the maxillary, frontal and the sphenoid paranasal sinus bones and retain their ostia at the location of the initial evagination. ${ }^{11}$ The ostia remain as their pathway for drainage. The anterior ethmoidal cells those are arising from the middle meatus penumatize the middle turbinate in approximately $55 \%$ cases, which often drain into the frontal recess. ${ }^{12}$ Posterior ethmoidal cells arising from the superior meatus penumatize the middle turbinate in approximately $45 \%$ of the cases and they often drain into retro-bulbar recess. ${ }^{12}$ Most often the drainage occurs through the conchal ostium found near the frontal recess area into which the frontal sinus drains. The middle turbinate concha bullosa is apparent after 7 to 8 years of age and it continues to develop even after the period of adolescence. ${ }^{13}$ The degree of pneumatization of the middle turbinate and the inflammatory changes within the concha bullosa relates with the clinical presentation and severity of the symptoms. There are studies which show that concha bullosa ostium drain mostly to the frontal recesses, less commonly to the adjacent air cells through the basal lamina and to the hiatus semilunaris. ${ }^{14,15}$ The pneumatization of the middle turbinate is classified into three groups such as lamellar type where pneumatization is found in the vertical lamella, bulbous type where pneumatization is found in bulbous segment and the pneumatization at both lamellar and bulbous portions is called extensive type of concha bullosa. ${ }^{16}$

\section{EPIDEMIOLOGY}

The incidence of the middle turbinate concha bullosa is between 13 and 33.6\%. ${ }^{17}$ The incidence of CT findings for middle turbinate concha bullosa has ranged from 14-53\% and its relationship to paranasal sinus disease continues to be debated. ${ }^{18}$ One study showed that the percentage of the 
concha bullosa was $76.4 \% .{ }^{19}$ One study documented the prevalence the concha bullosa which varies from 5 to $53 \%$ where author noted middle turbinate pneumatization in $9 \%$ of the 1000 lateral nasal specimens. ${ }^{20}$ As per Turner, the incidence of the concha bullosa is $53.6 \%$ and Maru et al found it out to be $41.3 \%$ while approximately $15 \%$ as seen by Bharathi et al. ${ }^{21-23}$ Depending on the location of the pneumatization, the middle turbinate concha bullosa is classified into extensive, bulbous and lamellar types. The prevalence of the middle turbinate concha bullosa of extensive, bulbous and lamellar types are $49.5 \%, 28.3 \%$ and $22.2 \%$ respectively. ${ }^{24}$

\section{PATHOPHYSIOLOGY}

On each side of the nasal cavity, there is presence of superior, middle and inferior turbinates. It is widely thought that the osteomeatal obstruction can impede ventilations of the paranasal sinuses and their mucociliary clearance which predispose to sinusitis. ${ }^{25}$ Concha bullosa intruding into the middle meatus may fill the area between the nasal septum and lateral wall impinging on the infundibulum and maxillary sinus ostium resulting areas of the mucosal contact and alters normal airflow, so producing negative influence on the ventilations of the paranasal sinuses and on mucociliary clearance in osteomeatal complex thus making the relevant paranasal sinus prone to infections. ${ }^{26}$

Stammberger documented two hypotheses for development of the middle turbinate concha bullosa. ${ }^{27}$ First one suggests, deviated nasal septum provides a large contralateral concave nasal space (e vacuo) for hypertrophy or expansion of the middle turbinate resulting in concha bullosa formation. Second hypothesis suggest, both concha bullosa of the middle turbinate and deviated nasal septum are two incidental coexisting findings. ${ }^{27}$ This study is against the e vacuo hypothesis as concha bullosa was not statistically more likely to cause deviated nasal septum to the contralateral side and there is no statistical relationship between one side or bilateral concha bullosa with deviated nasal septum. One study stated a statistically significant relationship between the deviated nasal septum and one side but not bilateral concha bullosa. ${ }^{28}$

Middle turbinate concha bullosa may obstruct the osteomeatal complex and leads to sinusitis. However there is lesser understanding about the middle turbinate concha bullosa contributing towards the sinusitis. The middle turbinate concha bullosa is three types such as lamellar (vertical lamella of middle turbinate pneumatization), bulbous type (inferior part of middle turbinate pneumatization) and extensive type (vertical and inferior part of the middle turbinate pneumatization).The diseases of the sinonasal tract can affect the concha bullosa, leading to mucosal thickening, retention of the mucous secretion, mucocele and pyocele within the middle turbinate concha bullosa. The concha bullosa itself result in mechanical obstruction and hamper the drainage pathway and result in sinusitis. Proper understanding of the anatomical variation of the middle turbinate concha bullosa is helpful for appropriate management. Sometimes the rare anatomical variations of the middle turbinate concha bullosa such as extensive thickening within the concha bullosa, air cells inside the concha bullosa and mucopyocele of the concha bullosa may result in orbital complications. ${ }^{29}$ The concha bullosa rarely filled with pus and fluid which results in mucopyocele. This happens due to chronic obstruction of the concha bullosa ostium, which obstruct the optimal air current flow between the concha bullosa cavity and the surrounding structures such as ethmoidal cells, frontal recess or middle meatus. 30 For this reason, the epithelial lining of the concha bullosa mucocele/pyocele remains intact which is lacking in other types of mucocele. ${ }^{30}$

\section{CLINICAL MANIFESTATIONS}

The middle turbinate concha bullosa is usually asymptomatic and detected incidentally during endoscopic examination of the nasal cavity or CT scan of the paranasal sinuses. If the middle turbinate concha bullosa is over pneumatized, it can result in nasal obstruction, contact headache. ${ }^{31}$ It can also cause deviated nasal septum and chronic sinusitis which result in nasal block, epistaxis and headache. The concha bullosa may be unilateral or bilateral, so manifest symptoms in one side or both sides of the nasal cavity. Bilateral concha bullosa result in bilateral nasal obstruction. It may cause hyposmia when the concha bullosa obstruct the inspiratory air to reach the olfactory epithelium. The severity of the clinical presentations and symptoms depend on the degree of pneumatization and the inflammatory changes within the concha bullosa.

There is slight female preponderance of the chronic rhinosinusitis along with anatomical variation of the sinonasal tract with female to male ratio between 55 to $60 \%$ versus 40 to $45 \% .{ }^{32}$ Middle turbinate concha bullosa can occur in all age group, most probably reflects its embryological origin from ethmoidal air cell development. However, its clinical manifestations occur at different ages later on by influences of the allergy, trauma, environmental effect etc. The middle turbinate concha bullosa mucocele/pyocele can masquerade as tumors of the nasal cavity and so it is important to consider the concha bullosa mucocele/pyocele in the differential diagnosis. The mucosal thickening and polyp formation within the middle turbinate concha bullosa is an uncommon finding. The inner surface of the concha bullosa is lined by mucous membrane and any inflammation can incite mucosal hypertrophy and formation of the polyp. ${ }^{33}$

\section{DIAGNOSIS}

The diagnosis relies on the clinical judgment on basis of the patient's complaints and with help of anterior and posterior rhinoscopy. ${ }^{34} \mathrm{CT}$ scan of the nose and paranasal sinuses has become the gold standard for evaluation of the patients with middle turbinate concha bullosa and sinusitis. 
The concha bullosa is usually diagnosed by the CT scan of the paranasal sinuses (Figure 1). CT scan is helpful to study the effect of the concha bullosa on the lateral wall of the nasal cavity and osteomeatal unit. ${ }^{35} \mathrm{CT}$ scan of the nose and paranasal sinuses is an accurate method for evaluation of the concha bullosa of middle turbinate, other anatomical variations of the nose and sinuses along with sinusitis. ${ }^{36}$ Coronal plane of the CT scan of the nose and paranasal sinuses are used by the surgeons because of its similarity with the surgical orientation. The axial and coronal cuts of the paranasal sinuses of CT scan have a great role for identification of the concha bullosa and surrounding structures. ${ }^{37}$ On diagnostic nasal endoscopy, the concha bullosa appears as an enlarged head of the middle turbinate. ${ }^{38}$ A large size concha bullosa often impinge the osteomeatal area and obstruct the drainage of the paranasal sinuses leading to chronic sinusitis by interfering with mucociliary clearance of the osteomeatal complex. ${ }^{35}$ Incidence of sinusitis is commonly seen on the side of the concha bullosa. So, it concluded that the presence of the concha bullosa could predispose to the sinusitis.

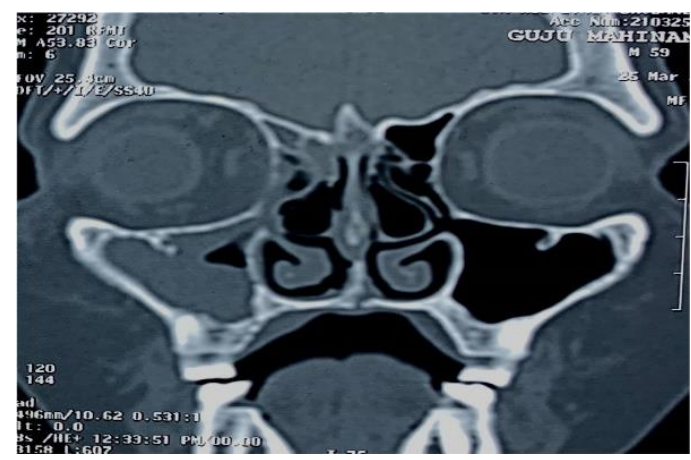

Figure 1: CT scan of the paranasal sinus showing bilateral concha bullosa with right side maxillary sinusitis.

\section{TREATMENT}

Most patients with middle turbinate concha bullosa are asymptomatic who do not need any intervention. The definitive treatment of the middle turbinate concha bullosa is surgery. However the medical treatment includes antibiotics, topical steroids spray, antihistamines. Topical nasal decongestant can also be helpful for short term relief of the symptoms by middle turbinate concha bullosa. The middle turbinate concha bullosa causing obstruction at the osteomeatal complex and results in symptoms often need surgery such as endoscopic sinus surgery. The symptomatic patients need endoscopic sinus surgery which includes resection of the concha bullosa and clearance of the sinus drainage pathway. ${ }^{39}$ Different surgical techniques include partial or complete resection of the concha bullosa, turbinoplasty and crushing. ${ }^{40}$ If there is deviated nasal septum, it also require septoplasty in the same sitting. Resection of the lateral lamella of the middle turbinate concha bullosa is an effective procedure and most common surgical technique utilized in case of the concha bullosa obstructing the osteomeatal complex. ${ }^{41}$
One author recommended a more conservative surgical technique for middle turbinate concha bullosa by submucosal resection. ${ }^{42}$ In case of bilateral concha bullosa, the lateral segments of the both bullous concha are excised endoscopically. Sometimes if it is associated with deviated nasal septum or spur, need endoscopic septoplasty. Crushing of the concha bullosa is a conservative technique which results in minimal injury to the mucosa. Although crushing of the concha bullosa is an easy technique and also more conservative one, the potential for formation of the concha again is still controversial. ${ }^{43}$

\section{CONCLUSION}

Chronic sinusitis is a serious health problem commonly found in routine clinical practice. Concha bullosa is a common anatomical variant seen in patients which result chronic sinusitis. Concha bullosa is pneumatization of the middle turbinate which hamper the drainage pathway of the osteomeatal complex where anterior group of paranasal sinuses drain into the nasal cavity. Otorhinolaryngologists, radiologists and clinicians should get awareness about the anatomical variants of the nasal cavity such as middle turbinate concha bullosa and its relationship with chronic sinusitis. The bulbous and extensive types of the middle turbinate concha bullosa are often symptomatic. Mucocele, pyocele and inflammatory mucosal thickening in the concha bullosa are more symptomatic but relatively uncommon in clinical practice. The definitive treatment of the symptomatic middle turbinate concha bullosa is surgery. Detailed knowledge of the anatomical variations of the concha bullosa is imperative for the operating surgeons.

Funding: No funding sources

Conflict of interest: None declared

Ethical approval: Not required

\section{REFERENCES}

1. Jena A, Swain SK. A study of anatomical variations in chronic rhinosinusitis with special reference to deviated nasal septum. IJAR. 2019;5(4):15-7.

2. AI-Rawi NH, Uthman AT, Abdulhameed E, AI Nuaimi AS, Seraj Z. Concha bullosa, nasal septal deviation and impacts on maxillary sinus volume among Emirati people: A cone-beam computed tomography study. Imaging science in dentistry. 2019;49(1):45.

3. Nouraei SA, Elisay AR, Dimarco A, Abdi R, Majidi $\mathrm{H}$, Madani SA et al. Variations in paranasal sinus anatomy: implications for the pathophysiology of chronic rhinosinusitis and safety of endoscopic sinus surgery. J Otolaryngol Head Neck Surg 2009; 38(1):32-37.

4. Sazgar AA, Massah J, Sadeghi M, Bagheri A, Rasool F. The incidence of concha bullosa and the correlation with nasal septal deviation. B ENT. 2008;4(2):87-92. 
5. Stallman JS, Lobo JN, Som PM. The incidence of concha bullosa and its relationship to nasal septal deviation and paranasal sinus disease. American Journal of Neuroradiology. 2004;25(9): 1613-8.

6. Li L, Zang H, Han D, Ramanathan Jr M, Carrau RL, London Jr NR. Impact of a concha bullosa on nasal airflow characteristics in the setting of nasal septal deviation: American journal of rhinology and allergy. 2020;34(4):456-62.

7. Kalaiarasi R, Ramakrishna V, Poyyamoli S. Anatomical variations of the middle turbinate concha bullos and its relationship with chronic sinusitis: a prospective radiologic study. International archives of otorhinolaryngology. 2018;22(3):297-302.

8. Dutta M. Concha bullosa:the pitcher in the nose with hidden diseases. Ear, Nose and Throat 2020;99(2):15-6.

9. EI-Anwar MW, Ali AH, Almolla RM, Abdulmonaem G, Raafat A, Hassan ME. Radioloigcal middle turbinate variations and their relation to nasal septum deviation in asymptomatic adult. Egyptian journal of radiology and nuclear medicine. 2020;51(1):1-5.

10. Zinreich S, Albayram S, Benson M, Oliverio P. The ostiomeatal complex and functional endoscopic surgery. In: Som P, ed. Head and Neck Imaging. 4th ed. St Louis: Mosby. 2003;149-73.

11. Zinreich SJ, Mattox DE, Kennedy DW, Chisholm HL, Diffley DM, Rosenbaum AE. Concha bullosa: CT evaluation. J Comput Assist Tomogr. 1988;12(05):778-84.

12. Van Alyea OE. Nasal sinuses: an anatomic and clinical consideration. Baltimore: Williams and Wilkins. 1951.

13. Cohen SD, Matthews BL. Large concha bullosa mucopyocele replacing the anterior ethmoid sinuses and contiguous with the frontal sinus. Ann Otol Rhinol Laryngol. 2008;117(01):15-7.

14. Ünlü HH, Akyar S, Çaylan R, Nalça Y. Concha bullosa. J Otolaryngol. 1994;23:23-7.

15. Lidov M, Som PM. Inflammatory disease involving a concha bullosa (enlarged pneumatized middle nasal turbinate): MR and CT appearance. AJNR Am J Neuroradiol. 1990;11:999-1001.

16. Bolger WE, Butzin CA, Parsons DS. Paranasal sinus bony anatomic variations and mucosal abnormalities: CT analysis for endoscopic sinus surgery. Laryngoscope. 1991;101:56-64.

17. Lee JH, Hong SL, Roh HJ, Cho KS. Concha bullosa mucocele with orbital invasion and secondary frontal sinusitis: a case report. BMC Res Notes. 2013;6(06):501.

18. Lloyd G, Lund V, Scadding G. CT of the paranasal sinuses and functional endoscopic surgery: a critical analysis of 100 symptomatic patients. J Laryngol Otol. 1991;105:181-5.

19. Tiwari R, Goyal R. Role of concha bullosa in chronic rhinosinusitis. Indian J Otolaryngol Head Neck Surg. 2019;71(1):128-31.
20. Lothrop HA. The anatomy of the inferior ethmoidal turbinate bone with particular reference to cell formation: surgical importance of such ethmoid cells. Ann Surg. 1903;38:233-55.

21. Turner AL. Disease of the nose, throat and ear for practitioners and students, 2nd edn. John Wright and Sons, Bristol (quoted by -Bolger WE, Butzin CA, Parson DS. Paranasal sinus bony anatomic variations and mucosal abnormalities; CT analysis for endoscopic sinus surgery. Laryngoscope.1991;101:56-64.

22. Maru YK, Gupta Y. Concha bullosa: frequency and appearance on sinonasal CT.Indian J Otolaryngol Head Neck Surg. 2000;52:40-4.

23. Bharathi MB, Mamtha H, Prasanna LC. Variations of osteomeatal complex and its applied anatomy: a CT scan study. Indian J Sci Technol. 2010;3(8):904-7.

24. Kalaiarasi R, Ramakrishnan V, Poyyamoli S. Anatomical Variations of the Middle Turbinate Concha Bullosa and its Relationship with Chronic Sinusitis: A Prospective Radiologic Study. Int Arch Otorhinolaryngol. 2018;22:297-302.

25. Bolger WE, Parsons DS, Butzin CA. Paranasal sinus bony anatomic variations and mucosal abnormalities: CT analysis for endoscopic sinus surgery. The Laryngoscope. 1991;101(1):56-64.

26. Stammberger $\mathrm{H}$, Wolf $\mathrm{G}$. Headaches and sinus diseases:the endoscopic approach. Ann Otol Rhinol Laryngol. 1988;97(134):3-23.

27. Stammberger H. In: Functional endoscopic sinus surgery, the Messerklinger technique. Philadelphia: B.C. Decker. 1991:156-68.

28. Aktas D, Kalcioglu MT, Kutlu R, Ozturan O, Oncel $\mathrm{S}$. The relationship between the concha bullosa, nasal septal deviation and sinusitis. Rhinol. 2003;41:1036.

29. Kalaiarasi R, Ramakrishnan V, Poyyamoli S. Anatomical Variations of the Middle Turbinate Concha Bullosa and its Relationship with Chronic Sinusitis: A Prospective Radiologic Study. Int Arch Otorhinolaryngol. 2018;22:297-302.

30. Lee JS, Ko IJ, Kang HD, Lee HS. Massive concha bullosa with secondary maxillary sinusitis. Clin Exp Otorhinolaryngol. 2008;1(04):221-3.

31. Swain SK, Behera IC, Mohanty S, Sahu MC. Rhinogenic contact point headache-Frequently missed clinical entity.Apollo Medicine. 2016;13(3):169-73.

32. Nadas S, Duvoisin B, Landry M, Schnyder P. Concha bullosa: frequency and appearances on CT and correlations with sinus disease in 308 patients with chronic sinusitis. Neuroradiol. 1995;37:234-7.

33. Erkan AN, Canbolat T, Ozer C, Yilmaz I, Ozluoglu LN. Polyp in concha bullosa:a case report and review of the literature.Head Face Med. 2006;2(02):11.

34. Swain SK, Mohanty JN. Chondroma of the nose. Libyan Journal of Medical Sciences. 2020;4(2):87.

35. Swain SK, Das A, Sahu MC. Anatomical variations of nose causing rhinogenic contact point headache- a 
study at a tertiary care hospital of eastern India. Polish Ann Med. 2018;25(1):1-4.

36. Bolger WE, Butzin CA, Parsons DS. Paranasal sinus bony anatomic variations and mucosal abnormalities: CT analysis for endoscopic sinus surgery. Laryngoscope. 1991;101(1 Pt 1):56-64.

37. Swain SK, Behera IC, Sahu MC. Primary sinonasal tuberculosis: Our experiences in a tertiary care hospital of eastern India. Egyptian J Ear Nose Throat Allied Sci. 2017;18(3):237-40.

38. Swain SK, Sahu MC, Banerjee A. Non-sinonasal isolated facio-orbital mucormycosis-a case report. Jde Mycologie Medicale. 2018;28(3):538-41.

39. Swain SK, Debta P, Samal S, Mohanty JN, Debta FM, Dani A. Endoscopic treatment of sinonasal ossifying fibroma: A case report. Indian J Public Health. 2019;10(9):1697.

40. Kieff DA, Busaba NY. Reformation of concha bullosa following treatment by crushing surgical technique :implication for balloon sinusplasty. Laryngoscope. 2009;119:2454-6.

41. Caughey RJ, Jameson MJ, Gross CW, Han JK. Anatomic risk factors for sinus disease: fact or fiction? Am J Rhinol. 2005;19:334-9.

42. Bhatt NJ. Endoscopic Sinus Surgery: New Horizons, London: Singular Publishing Group. 1997.

43. Dogru H, Uygur K, Tuz M. Concha bullosa squeezer for turbinoplasty (Dogru forceps). J Otolaryngol. 2004;33:111-3.

Cite this article as: Swain SK. Middle turbinate concha bullosa and its relationship with chronic sinusitis: a review. Int J Otorhinolaryngol Head Neck Surg 2021;7:1062-7. 